\title{
PROFIL PROGNASI WAJAH BEBERAPA POPULASI DUNIA (Prognation Profile of World Population Faces)
}

\section{Toetik Koesbardiati}

Departemen Antropologi FISIP UNAIR Jl. Dharmawangsa Dalam, Surabaya 60286

e-mail: toetik.koesbardiati@gmail.com

\begin{tabular}{l} 
INFO ARTIKEL \\
\hline Histori Artikel \\
Diterima: 3 Juli 2017 \\
Direvisi: 10 Juli 2017 \\
Disetujui: 30 Oktober 2017
\end{tabular}

Keywords:

anthropometry,

face prognosis,

forensic anthropology,

bioarchaeology

Kata kunci:

antropometri, prognasi wajah,

antropologi forensik, bioarkeologi

\begin{abstract}
The face is one of the major variables in determining the biological characteristics of a population in the identification effort of human skeletal remains. This is not only important in the field of forensic anthropology but also the field of bioarchaeology. The purpose of this study is to describe the variation of facial angle in some of the world population. The method applied is anthropometry. The study material is the skull of nine world populations of Europe, North Africa, Subsahara Africa, South America, Inuit, Australomelanesia, Indonesia, Polynesia and China. The results showed that among the population tested, Australomelanesoid, Polynesian, Indonesian and African Subsahara populations had a prognathic face both on the even face, as well as the alveolar and facial projection. In contrast, the population groups of China, Europe, Inuit and North Africa are population groups that have faces of orthognath.
\end{abstract}

\begin{abstract}
ABSTRAK
Wajah adalah salah satu variabel utama dalam menentukan ciri biologis suatu populasi pada usaha identifikasi sisa rangka manusia. Hal ini tidak hanya panting dalam bidang antropologi forensik tetapi juga bidang bioarkeologi. Tujuan penelitian ini adalah untuk mendeskripsikan variasi sudut wajah pada beberapa populasi dunia. Metode yang diterapkan adalah antropometri. Bahan penelitian adalah tengkorak dari sembilan populasi dunia yaitu populasi Eropa, Afrika Utara, Afrika Subsahara, Amerika Selatan, Inuit, Australomelanesia, Indonesia, Polinesia dan China. Hasil penelitian menunjukkan bahwa diantara populasi yang diuji, populasi Australomelanesoid, Polinesia, Indonesia dan Afrika Subsahara memiliki wajah yang prognath baik pada bagian wajah genap, maupun bagian alveolar serta proyeksi wajah. Sebaliknya kelompok populasi China, Eropa, Inuit dan Afrika Utara adalah kelompok populasi yang memiliki wajah orthognath.
\end{abstract}

\section{PENDAHULUAN}

Ketika tubuh manusia sudah berubah menjadi rangka, maka data demografis seperti jenis kelamin, umur, tinggi badan, maupun ciri populasi tidak lagi dapat dikenali dengan mudah. Beberapa metode dikembangkan demi mendapatkan data demografs. Ahli Antropologi banyak meneliti terkait dengan data ciri demografis populasi- juga disebut sebagai ethnic origins atau populasi dunia untuk memudahkan mengenali ciri demografis ini. Dengan mengetahui ciri demografis pada rangka dapat membantu identifikasi sisa rangka manusia baik dari aspek forensik maupun dari aspek bioarkeologi.

Ras merupakan klasifikasi biologis manusia di bawah taxon spesies (Redaksi, 2008: 188). Ras atau 
variasi populasi semakin menjadi hal yang sulit untuk ditentukan. Byers (2008) menyebutkan bahwa penentuan ras yang paling mudah adalah pada bagian wajahnya. Perkembangan teknologi memudahkan manusia berpindah tempat secara cepat. Perpindahan penduduk dari satu tempat ke tempat lain, baik yang bersifat politis, ekonomis maupun edukatif dan alasan lainnya membuka peluang terjadinya kawin campur. Besarnya arus migrasi dari satu tempat ke tempat lain juga membuka peluang terjadinya kawin campur. Percampuran perkawinan ini akan membaurkan ciri genetis dalam suatu populasi yang berdampak juga terhadap ciri yang bersifat fenotipis. Dengan demikian kawin campur meningkatkan tendensi menurunnya perbedaan antar populasi. Oleh karena itu penentuan ras dalam identifikasi forensik maupun dalam analisis bioarkeologi menjadi lebih sulit karena persoalan tersebut di atas.

Dari aspek genetika, disebutkan oleh Foster dan Sharp (2002), bahwa ras tidak relevan. Ras adalah persoalan konstruksi sosial. Variasi genetik tidak merefleksikan perbedaan ras. Namun demikian Foster dan Sharp tidak mengabaikan bahwa ras dalam pengertian sosial dapat menjadi awalan yang baik untuk mengumpulkan data genetik. Lebih jauh, Jorde dan Wooding (2004) menyatakan bahwa beda antar populasi (antar kontinen) hanya sebesar $10 \%$, sedangkan beda dalam populasi (dalam satu kontinen) menunjukkan persentasi yang lebih besar (90\%).
Hal ini menunjukkan bahwa masih ada ciri suatu populasi yang masih dapat digunakan sebagai petanda sekalipun mungkin tumpang tindih dengan populasi lain.

Studi mengenai rangkarangka dan gigi-geligi manusia dalam perkembangannya telah banyak dilakukan dan dilibatkan dalam berbagai rancangan penelitian arkeologi. Dijelaskan oleh Larsen (2000) bahwa hal tersebut berkaitan dengan berbagai hipotesis yang berkembang pesat dalam studi arkeologi, terutama mengenai permasalahan demografi dan gaya hidup masyarakat prasejarah. Faktor lain yang mempengaruhi adalah fakta bawah rangka dan gigi sebagai jaringan keras dalam tubuh bisa memberikan banyak informasi mengenai kondisi biologis dan kehidupan sosial-budaya manusia masa lampau, baik dalam tingkat individu maupun populasi.

Brothwell (1965) menegaskan bahwa temuan sisa rangka dan gigi manusia bisa digunakan untuk merekonstruksi kehidupan masyarakat prasejarah. Melalui analisis temuan rangka-rangka dan gigi-geligi dapat diketahui berbagai hal mengenai karakteristikfisikindividual, seperti afiliasi populasi, umur, jenis kelamin, dan gambaran perawakan fisiknya. Informasi lain yang bisa diperoleh dari temuan arkeologis sisa rangka dan gigi manusia adalah mengenai diet atau pola makan, kondisi kesehatan, penyakit, dan aktivitas fisik yang dilakukan oleh individu di masa lampau (Brothwell, 1965; Jacob, 1982). 
Tujuan penelitian ini adalah (sudut zygomaksila) juga diukur. Metode untuk mendeskripsikan profil prognasi yang digunakan adalah antropometri wajah pada sembilan populasi di dunia. (osteometri) menurut Martin yang ditulis Dengan mengetahui ciri profil wajah dapat membantu analisis demografi baik untuk kepentingan forensik maupun bioarkeologi.

\section{Bahan dan Metode}

Bahan penelitian adalah tengkorak berasal dari sembilan populasi yang terdiri dari populasi China, Indonesia, Inuit, Amerika Selatan, Australomelanesia, Polinesia, Afrika Sub-Sahara, Afrika Utara, dan Eropa. Keseluruhan sampel adalah 256 tengkorak. Sampel dipilih secara acak dan tidak dibedakan antara sampel dengan jenis kelamin laki-laki maupun perempuan.

Data yang dikumpulkan adalah sudut wajah yang terdiri dari sudut wajah genap, sudut alveolar dan gnathic index. Ketiga ukuran sudut ini menunjukkan perkembangan wajah secara sagital sehingga dapat memberikan gambaran prognasi wajah. Selain sudut dari aspek anterior, sudut wajah dari aspek lateral ulang oleh Bräuer (dalam Knussman, 1988).

Sudut wajah genap diukur dari nasion $(\mathrm{n})$ ke prostion $(\mathrm{pr})$ dengan relasi terhadap Frankfurt Horizontal (FH). Sudut alveolar diukur dari subnasal (ns) ke prostion (pr) dalam relasi ke Frankfurt Horizontal. Sedangkan gnathic index diukur berdasarkan ukuran nasionprostion (n-pr) dan basion-prostion (bapr). Sudut zygomaksilaris diukur dari lebar bimaksila (zm-zm) dan subtense nya sehingga membentuk segitiga yang dapat diukur sudutnya (sudut zygomaksilaris). Ukuran sudut didapat dengan rumus $\tan (1 / 2 \alpha)=1 / 2 \mathrm{~F} / \mathrm{G} . \mathrm{F}$ adalah lebar wajah (zm-zm) sedangkan $G$ adalah subtense.

Untuk mendapatkan gambaran umum populasi, data dianalisis melalui uji statistik deskriptif. Dengan demikian didapatkan gambaran umum tendensi masing-masing populasi pada setiap variabel yang diuji. Test anova dilakukan untuk menguji perbedaan antar populasi.

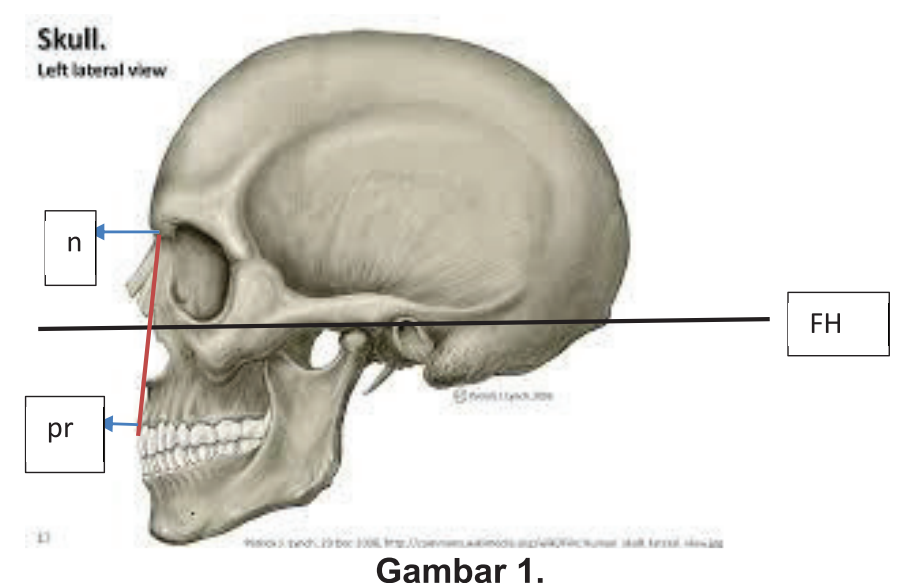

Sudut wajah genap. Diukur dari nasion $(\mathrm{n})$-prosthion $(\mathrm{pr})$ dengan relasi terhadap Frankfurt Horizontal (FH) 


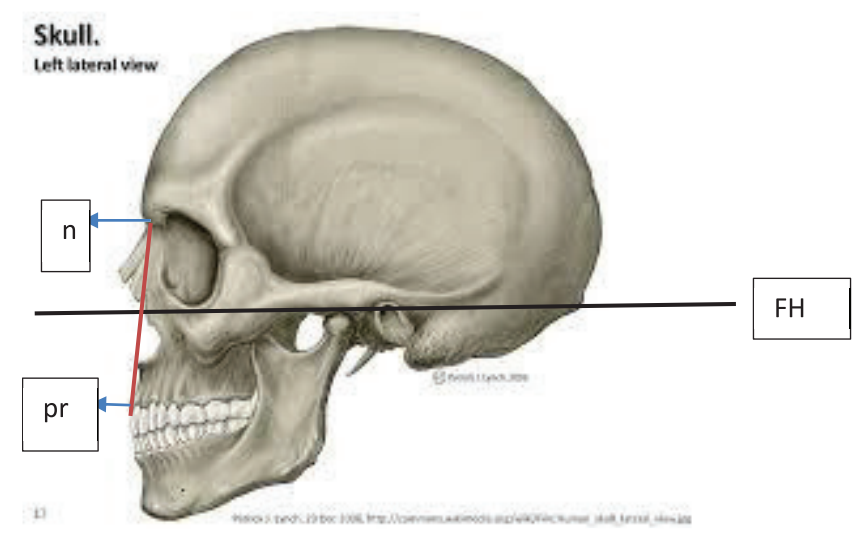

Gambar 2.

Sudut alveolar. Diukur dari nasospinale/subnasal (ns) - prosthion (pr) dengan relasi terhadap Frankfurt Horizontal (FH)

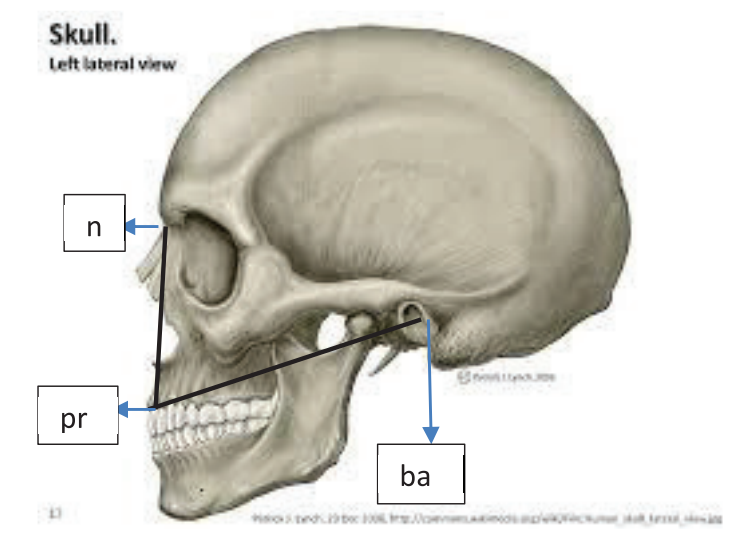

\section{Gambar 3.}

Gnathic Index. Diukur berdasarkan nasion (n) - prosthion (pr) dan prosthion (pr) dan basion (ba). Basion terletak di dasar tengkorak yaitu di pinggir anterior foramen occipital magnum.
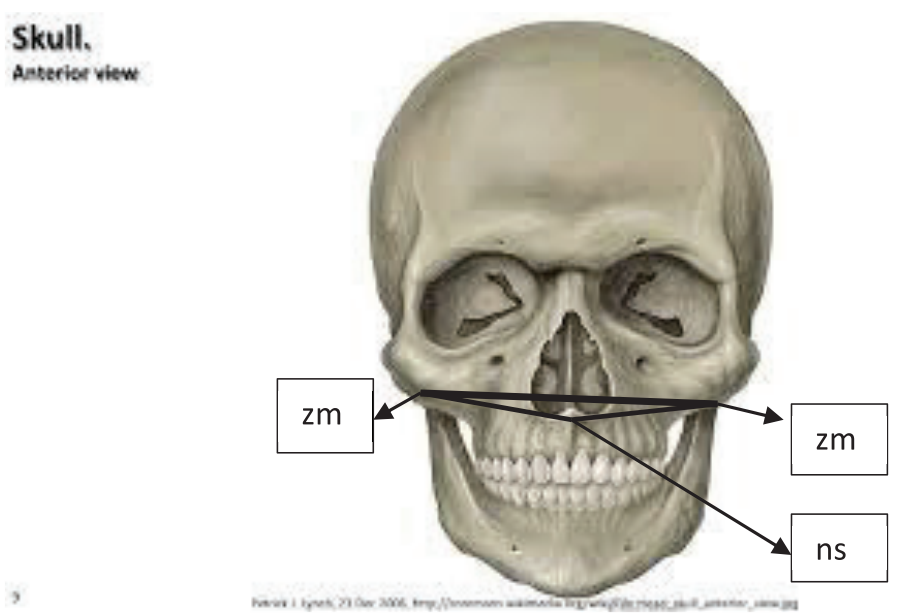

Gambar 4.

Sudut zygomaksilaris. Diukur berdasarkan lebar kedua titik zygomaksila (zm-zm) dan subtense antara bizygomaksila dan nasospinal (ns). Sudut zygomaksila menunjukkan derajat prognasi wajah tengah. Semakin kecil sudut yang dihasilkan berarti semakin tampak proyeksi wajah tengahnya. 


\section{Kategori}

Berikut adalah kategori untuk setiap sudut yang diukur dari variabel sudut wajah genap dan sudut alveolar (Knussmann, 1988):

Sudut wajah genap

1. Hyperprognath

$<70^{\circ}$
$70^{\circ}-<80^{\circ}$
$80^{\circ}-<85^{\circ}$
$85^{\circ}-<93^{\circ}$
$\geq 93^{\circ}$

Sudut Alveolar

2. Prognath

6. Ultraprognath

$<60^{\circ}$

3. Mesognath

7. Hyperprognath

$60^{\circ}-<70^{\circ}$

4. Orthognath

8. Prognath

$70^{\circ}-<80^{\circ}$

5. Hyperorthognath

9. Mesognath

$80^{\circ}-<85^{\circ}$

10. Orthognath

$85^{\circ}-<93^{\circ}$

11. Hyperorthognath $\geq 93^{\circ}$

\section{PEMBAHASAN}

Berdasarkan hasil pengukuran didapat beberapa ukuran sudut dan perhitungan indeks. Hasil ukuran ditampilkan dalam bentuk statistic deskriptif yang memberi gambaran mengenai rerata hitungan dan standard deviasi (sd).

1. Sudut wajah genap (Profile angle)

Tabel 1. Sudut wajah genap

\begin{tabular}{|l|c|c|c|}
\hline \multicolumn{1}{|c|}{ Sampel } & N & $\begin{array}{c}\text { Mean } \\
\text { (dalam derajat) }\end{array}$ & Sd \\
\hline China & 41 & 88.56 & 3.47 \\
\hline Indonesia & 24 & 85.92 & 3.08 \\
\hline Inuit & 16 & 88.19 & 3.12 \\
\hline Amerika Selatan & 19 & 87.84 & 4.60 \\
\hline Australomelanesia & 35 & 85.11 & 4.04 \\
\hline Polinesia & 11 & 86.45 & 4.23 \\
\hline Afrika subsahara & 45 & 85.93 & 3.81 \\
\hline Afrika Utara & 15 & 88.47 & 4.89 \\
\hline Eropa & 49 & 87.08 & 3.83 \\
\hline Total & 255 & 86.92 & 3.89 \\
\hline
\end{tabular}

Tabel 1 menunjukkan rerata sudut ortognath yaitu antara nilai $85^{\circ}-<93^{\circ}$. wajah genap dan standar deviasi pada Dari sembilan populasi ini, populasi sembilan populasi yang diteliti. Hasil uji China menunjukkan wajah yang paling Anova menunjukkan perbedaan mean orthognath (datar), diikuti oleh populasi yang signifikan antara sembilan sampel dari Afrika Utara dan Inuit. Sebaliknya $(F=3.32, p<0.05)$. Berdasarkan kategori, sekalipun semua populasi terpilih berada semua sampel berada dalam kategori dalam kriteria orthognath, Populasi 
Australomelanesia menunjukkan wajah kecenderungan prognath lainnya yang paling prognath dan berbeda adalah populasi Indonesia dan Afrika signifikan dengan populasi China yang Subsahara.

paling orthognath. Populasi dengan

2. Sudut alveolar (alveolar profile angle)

Tabel 2. Sudut alveolar

\begin{tabular}{|l|c|c|c|}
\hline \multicolumn{1}{|c|}{ Sampel } & $\mathrm{N}$ & $\begin{array}{c}\text { Mean } \\
\text { (dalam derajat) }\end{array}$ & Sd \\
\hline China & 41 & 67.17 & 6.22 \\
\hline Indonesia & 24 & 62.58 & 3.08 \\
\hline Inuit & 16 & 67.94 & 4.92 \\
\hline Amerika Selatan & 19 & 69.42 & 6.51 \\
\hline Australomelanesia & 35 & 55.94 & 7.41 \\
\hline Polinesia & 11 & 63.64 & 6.98 \\
\hline Afrika subsahara & 45 & 63.02 & 7.60 \\
\hline Afrika Utara & 15 & 69.40 & 6.64 \\
\hline Eropa & 49 & 75.33 & 5.38 \\
\hline Total & 255 & 66.23 & 8.87 \\
\hline
\end{tabular}

Rerata sudut alveolar (alveolar menunjukkan pola yang sama pada angle) seluruh populasi adalah bagian alveolamya.

$66.23^{\circ}$. Dari sembilan populasi yang Populasi lain yang memiliki diukur, populasi Australomelanesia tendensi sudut alveolar tajam adalah menunjukkan sudut alveolar yang paling Indonesia dan Polinesia. Dengan tajam $\left(55.94^{\circ}\right)$ dan masuk dalam kategori kata lain, populasi Australomelanesia, ultraprognathous. Sebaliknya populasi Indonesia dan Polinesia adalah populasi Eropa adalah populasi yang memiliki yang cenderung memiliki daerah alveolar sudut alveolar paling besar $\left(75.33^{\circ}\right)$. yang prognath. Di sisi lain, populasi Hal ini menunjukkan bahwa populasi Inuit, Amerika Selatan dan Afrika Utara Australomelanesia memiliki bagian menunjukkan tendensi sudut alveolar alveolar (sudut aleveolar) yang paling yang besar. Dengan kata lain, populasiprognath, dibanding dengan populasi populasi Eropa, Inuit, Amerika Selatan Eropa yang dalam hal ini memiliki dan Afrika adalah kelompok populasi bagian alveolar yang paling datar. yang memiliki daerah alveolar yang Populasi China dan Afrika Subsahara relative datar. 
Tabel 3. Gnathic index

\begin{tabular}{|l|c|c|c|}
\hline Sampel & $\mathrm{N}$ & Mean & Sd \\
\hline China & 41 & 96.34 & 4.45 \\
\hline Indonesia & 24 & 99.20 & 3.97 \\
\hline Inuit & 16 & 96.68 & 3.62 \\
\hline Amerika Selatan & 19 & 97.42 & 4.66 \\
\hline Australomelanesia & 36 & 101.44 & 4.04 \\
\hline Polinesia & 11 & 98.35 & 6.01 \\
\hline Afrika subsahara & 45 & 98.88 & 3.83 \\
\hline Afrika Utara & 15 & 95.37 & 3.48 \\
\hline Eropa & 49 & 95.40 & 3.61 \\
\hline Total & 256 & 97.72 & 4.51 \\
\hline
\end{tabular}

Gnathic index dimaksudkan

untuk melihat derajat prognasi wajah berdasarkan ukuran tinggi wajah dan panjang kepala. Dari perhitungan gnathic index ditemukan variasi yang lebar, yaitu dari orthognathic $(x-<97.9)$ hingga mesognathic (98.0-102.9). Berdasarkan klasifikasi gnathic index, populasi Eropa dan Afrika Utara menunjukkan derajat prognasi wajah yang rendah. Dengan kata lain, populasi Eropa dan Afrika Utara memiliki wajah yang ortognath. Populasi China, Amerika Selatan dan Inuit bertendensi memiliki wajah yang ortognath mendekati populasi Eropa dan Afrika Utara.

4. Proyeksi wajah tengah
Populasi yang memiliki wajah dalam kategori prognath adalah Polinesia, Afrika Subsaharan, Indonesia dan Australomelanesia. Dari empat populasi dengan kategori prognath, Australomelanesia menunjukkan nilai gnathic index yang paling tinggi, menunjukkan bahwa populasi Australomelanesia memiliki wajah yang paling prognath dibanding dengan populasi lainnya. Populasi Indonesia memiliki kecenderungan prognasi wajah yang sama dengan populasi Australomelanesia.

Tabel 4. Lebar wajah tengah (zm-zm)

\begin{tabular}{|l|c|c|c|}
\hline Sampel & $\mathrm{N}$ & Mean & Sd \\
\hline China & 41 & 97.49 & 4.45 \\
\hline Indonesia & 24 & 98.00 & 5.04 \\
\hline Inuit & 16 & 94.63 & 6.33 \\
\hline Amerika Selatan & 19 & 100.74 & 4.92 \\
\hline Australomelanesia & 36 & 92.78 & 5.49 \\
\hline Polinesia & 11 & 95.18 & 6.72 \\
\hline Afrika subsahara & 45 & 96.84 & 5.01 \\
\hline Afrika Utara & 15 & 95.20 & 4.96 \\
\hline Eropa & 49 & 91.96 & 5.43 \\
\hline Total & 256 & 95.53 & 6.12 \\
\hline
\end{tabular}


Tabel 5. Subtense bimaksila

\begin{tabular}{|l|c|c|c|}
\hline Sampel & $\mathrm{N}$ & Mean & Sd \\
\hline China & 41 & 21.83 & 2.44 \\
\hline Indonesia & 24 & 22.75 & 2.67 \\
\hline Inuit & 16 & 20.38 & 2.63 \\
\hline Amerika Selatan & 19 & 23.95 & 2.25 \\
\hline Australomelanesia & 36 & 24.67 & 2.33 \\
\hline Polinesia & 11 & 25.00 & 2.32 \\
\hline Afrika subsahara & 45 & 23.27 & 2.58 \\
\hline Afrika Utara & 15 & 23.27 & 2.66 \\
\hline Eropa & 49 & 22.45 & 2.22 \\
\hline Total & 256 & 22.97 & 2.66 \\
\hline
\end{tabular}

Tabel 6. Sudut zygomaksila

\begin{tabular}{|l|c|c|c|}
\hline Sampel & $\mathrm{N}$ & Mean & Sd \\
\hline China & 41 & 131.67 & 5.55 \\
\hline Indonesia & 24 & 130.18 & 5.67 \\
\hline Inuit & 16 & 133.42 & 5.06 \\
\hline Amerika Selatan & 19 & 129.13 & 4.52 \\
\hline Australomelanesia & 36 & 123.98 & 4.39 \\
\hline Polinesia & 11 & 124.55 & 4.07 \\
\hline Afrika subsahara & 45 & 128.71 & 4.83 \\
\hline Afrika Utara & 15 & 127.96 & 4.81 \\
\hline Eropa & 49 & 127.99 & 4.81 \\
\hline Total & 256 & 128.62 & 5.39 \\
\hline
\end{tabular}

Tabel 4 adalah gambaran segitiga yang dapat diukur sudutnya lebar wajah dari populasi yang diukur. untuk memberi gambaran proyeksi Berdasarkan aspek lebar wajah wajah tengah. Proyeksi wajah tengah yang diukur dari titik zygomaksilaris, menunjukkan prognasi bagian lateral menunjukkan bahwa diantara sembilan wajah. Tabel 6 menunjukkan bahwa populasi ini, yang memiliki wajah paling populasi Inuit memiliki sudut yang paling lebar adalah populasi Amerika Selatan, besar $\left(133^{\circ}\right)$, mengindikasikan wajah lalu disusul oleh populasi Indonesia dan yang sangat datar, disusul oleh populasi China. Sedangkan dari aspek subtense China $\left(131^{\circ}\right)$ dan populasi Indonesia seperti yang ditampilkan pada tabel $5,\left(130^{\circ}\right)$. Sebaliknya populasi Polinesia menunjukkan bahwa populasi Polinesia $\left(124^{\circ}\right)$ dan Australomelanesia $\left(123^{\circ}\right)$ dan Australomelanesia, Amerika Selatan menunjukkan proyeksi wajah yang serta populasi dari Afrika Utara dan prognath.

Afrika Subsahara memiliki subtense

Prognasi wajah baik dari aspek yang tinggi.

lateral maupun sagittalmemberi petunjuk

Dari variabel lebar wajah (zm- kekhasan suatu populasi, yang biasanya $\mathrm{zm}$ ) dan subtense ini kemudian didapat disebut ciri rasial. Berdasarkan variable- 
lingkungan. Tekanan lingkungan ini kemudian membawa dampak pada seleksi. Iklim dan temperatur diduga berperan penting dalam prognasi wajah. Secara geografis, populasi yang memiliki wajah prognath, baik dari aspek lateral maupun sagittal, berada di wilayah tropis. Kelompok ini adalah populasi Australomelanesia, Indonesia, Polinesia dan Afrika subsahara. Sebaliknya populasi yang memiliki wajah orthognath tersebar di wilayah bertemperatur rendah, yaitu kelompok ortognath yang terdiri dari kelompok populasi China, Eropa, Inuit, dan Afrika Utara.

Untuk membuktikan lebih jauh peran iklim dalam prognasi wajah, penting pula diketahui peran hidung (lebar dan tinggi hidung). Karena hidung adalah bagian utama dalam mekanisme adaptasi terhadap tekanan lingkungan (dalam hal ini adalah temperatur).

\section{PENUTUP}

Berdasarkan pengukuran variabel sudut wajah pada sembilan populasi yaitu populasi Eropa, Afrika Utara, Afrika Subsahara, Amerika Selatan, Inuit, Australomelanesia, Indonesia, Polinesia dan China diketahui bahwa ada variasi besar dan kecilnya sudut yang mengindikasikan derajat prognasi wajah pada masing-masing populasi. Dari empat sudut wajah yang diukur dan dianalisis, yaitu sudut wajah genap, sudut alveolar, sudut maksilaris dan gnathic index, diketahui bahwa populasi Australomelanesia, diikuti oleh populasi Polynesia, Indonesia dan Afrika Subsahara memiliki wajah yang paling prognath. Sebaliknya populasi Eropa diikuti oleh populasi China, Inuit dan Afrika Utara cenderung memiliki wajah yang orthognath.

Secara umum, ciri ini dapat digunakan sebagai bantuan dalam menentukan ethnic origin dalam usaha identifikasi di bidang antropologi forensik maupun bioarkeologi. Pola geografis dan frekuensi prognatisme dapat digunakan untuk memperkirakan ethnic origin suatu populasi. Sekalipun demikian hal ini tidak dapat menjadi patokan mutlak karena pengukuran dan perhitungan sudut wajah hanya melibatkan sembilan populasi. Dimungkinkan akan terjadi overlap pada populasi-populasi lain. Selain itu perlu ditambahkan beberapa variabel terkait prognathisme yang lain sehingga dapat diketahui lebih banyak pola porgnathisme. 


\section{DAFTAR PUSTAKA}

Bräuer, G. 1988. Osteometrie dalam Anthropologie, Martin and Knussman (eds). Fischer Verlag.

Byers, S. 2008. Introduction to Forensci Anthropology. Academic Press.

Brothwell, D. R. 1965. Digging up Bones. London: William Clowes and Sons Ltd.

Foster, M.W. dan Sharp, R.R. 2002. Race, Ethnicity and Genomics: Social Classifications as Proxies of Biological Heterogeneity. Genome Res. 12:844850.

Glenville, E.V. 1969. Nasal Shape, Prognahism and Adaptation in Man. Am. J. Phys. Vol 30 (1): 29-37.

Jacob, T. 1982. Prospek Penelitian Paleoanthropologi di Indonesia. Buletin Bioanthropology Indonesia. III (1): 47-55.

Jorde, L. dan Wooding S.P. 2004. Genetic Variation, Classification and Race. Nature genetics supplement, November vol. 35: 11.

Koesbardiati, T. 2000. On the Relevance of the Regional Continuity Features of the Face in East Asia. Dissertation. Hamburg Universitaet.

Larsen, C. S. 2000. Bioarchaeology: Interpreting Behavior from the Human Skeleton. New York: Cambridge University Press.

Redaksi, Dewan. 2008. Metode Penelitian Arkeologi. Jakarta: Pusat Penelitian dan Pengembangan Arkeologi Nasional. 